\title{
O OLHAR ERGONÔMICO NO USO DE ESPACCOS POR IDOSOS: UM ESTUDO DE CASO EM ÁREA DE SERVIÇO
}

\author{
SENA, Renan (1); \\ BARROS, Bruno (2) \\ (1) UFCG, Bacharel \\ e-mail:renan sena castro@hotmail.com \\ (2) UFPE, Mestre \\ e-mail:barros bruno@hotmail.com
}

\begin{abstract}
RESUMO
Com a melhoria na qualidade de vida da população brasileira, aumenta-se cada vez mais sua expectativa de vida e, consequentemente aumenta-se a população idosa. Nesse contexto, o presente trabalho aborda a questão da ergonomia ambiental em um estudo de caso envolvendo a área de serviço de uma habitação popular construída pela Caixa através do projeto "Minha casa, minha vida". Assim, utilizou-se a Metodologia para Projetos de Construção Centrados no Ser Humano. Os resultados da pesquisa chegaram a recomendações ergonômicas que consideram as limitações deste tipo de usuário, além do fato de que foram gerados parâmetros para novos projetos do gênero.
\end{abstract}

Palavras chave: idosos; ergonomia do ambiente construído; ambientes domésticos.

\begin{abstract}
Thanks to the improvement in the quality of life of the Brazilian population, their life expectancy increases, and consequently the elderly population increases. In this context, the present work addresses the issue of environmental ergonomics, a case study involving the service area of a popular housing built by Caixa through the project "Minha casa, minha vida". Where we used the Methodology for Human-Centered Construction Projects. The results of the research arrived at ergonomic recommendations that consider the limitations of this type of user, besides the fact that parameters were generated for new projects of the genre.
\end{abstract}

Keywords: elderly; built environment ergonomics; domestic environments.

\section{INTRODUÇÃO}

De acordo com os dados da ONU (2011), uma das grandes preocupações não está apenas no fato de o mundo ter atingido mais de 7 bilhões de habitantes, mas sim na tendência de crescimento da população com mais de 60 anos, que vai triplicar nos próximos 40 anos. Desta forma, precisaremos cada vez mais pensar em ambientes acessíveis para o usuário idoso.

Conforme o Relatório Mundial de Saúde e Envelhecimento, segundo a Organização Mundial da Saúde (OMS, 2015), o número de pessoas com mais de 60 anos no país deverá crescer muito mais rápido do que a média internacional. Enquanto a quantidade de idosos vai duplicar no mundo até o ano de 2050, ela quase triplicará no Brasil. 


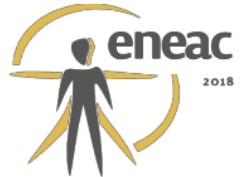

No Brasil, a porcentagem atual, de $12,5 \%$ de idosos, deve alcançar os $30 \%$ até a metade do século. Ou seja, logo, seremos considerados uma nação envelhecida - conforme a OMS, essa classificação é dada aos países com mais de 14\% da população constituída de idosos, como são, atualmente, França, Inglaterra e Canadá, por exemplo (OMS, 2015).

A área de serviço é um espaço de grande relevância em uma residência, porém sabemos que nem sempre esse espaço é construído de forma adequada ao seu usuário, principalmente quando esse usuário é idoso, que possui demandas específicas. Deste modo, fica difícil promover a autonomia do idoso face a um ambiente que oferece riscos. É necessário alertar a população dos riscos que esse espaço pode trazer, pois o uso do mesmo em desconformidade com o usuário pode vir a trazer vários perigos, como acidentes envolvendo quedas, choques com equipamentos, escorregões, choques elétricos, dentre vários outros problemas.

Dentro deste contexto, o presente trabalho apresenta um estudo de caso onde analisa um ambiente de área de serviço destinado a uma usuária idosa. Como estudo de caso, selecionou-se uma usuária idosa, que além de limitações geradas pelo processo natural de envelhecimento, ainda sofre com problemas como osteoporose, catarata e sofreu fraturas em algumas partes do corpo.

\section{FUNDAMENTAÇÃO TEÓRICA}

As condições de saúde em idosos têm apontado para direções acerca do envelhecimento populacional. Trata-se de um acontecimento que vem direcionado pela elevada taxa de morbidade ocasionada pelas deficiências, assim como as limitações funcionais, o que pode comprometer a independência e autonomia dos usuários, e tende a acarretar riscos aos distúrbios da mobilidade física (CLARES, FREITAS, BORGES, 2014). Alguns fatores de risco que são agregadas a mobilidade em relação as limitações do idoso, e estes podem ser sociais, organizacionais, individuais ou ambientais.

O ser humano começa a apresentar sinais de debilidade de sistemas orgânicos com o avançar da idade, bem como perdas de capacidades regenerativas. Além de que aparecem cada vez mais limitações, esse é o processo de envelhecimento fisiológico, que geralmente traz alguns impactos negativos, como rugas, manchas na pele, comprometimento visual e auditivo, perdas de memória, perdas de massa e redução de tônus muscular, perda de cálcio nos ossos, rigidez articular e redução da amplitude de movimento, além de alterações na marcha e no equilíbrio que podem acarretar em predisposição a quedas, dores e incapacidade funcional (CLARES, FREITAS, BORGES, 2014; OMS, 2012).

Dentre as limitações acarretadas pelo envelhecimento, destacam-se a frequência de doenças as quais esses usuários são acometidos. Um bom exemplo é a Osteoporose, que atinge boa parte da população idosa e trata-se de uma doença Osteometabólica. É uma doença esquelética sistêmica, caracterizada por massa óssea baixa e deterioração microarquitetural do tecido ósseo, conduzindo à fragilidade do osso e ao aumento do risco de fratura (SHAW \& WITZKE, 1998). A osteoporose, segundo Chau e Edelman (2002), causa invalidez pelas deformidades e incapacidades dos indivíduos afetados. A demora do tratamento de fraturas e outros problemas decorrentes da enfermidade causa um ônus elevado (NIGHTINGALE, HOLMES, MASON et al (2001).

Outro problema muito comum entre os idosos é a Catarata que, segundo Neto (2016), pode ter várias etiologias como, traumática, congénita, inflamatória, entre outras, porém a mais comum está relacionada ao avanço da idade, que é a catarata senil. Estima-se que mais de $50 \%$ das pessoas acima de 60 anos e algumas mais jovens sofrem catarata.

Ainda de acordo com Neto (2016), catarata é a turvação progressiva do cristalino, interferindo na absorção da luz que chega a retina, causando uma visão progressivamente 


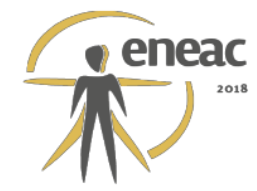

borrada. O portador de catarata geralmente incomoda-se quando exposto a luz forte, ou se ver halos ao redor das luzes. A mudança no grau dos óculos pode ajudar no começo, porém o avanço da catarata faz com que a visão vá diminuindo.

\section{METODOLOGIA}

Para guiar a condução procedimental de investigação, se fez necessária a aplicação da Metodologia para Projetos de Construção Centrados no Usuário, encontrada em Attaianese e Duca (2012). Ela consiste principalmente em projetar a construção dos ambientes considerando o ser humano. Essa metodologia é originalmente composta por 7 etapas, porém, neste estudo foram contempladas apenas as 4 primeiras, pois o objetivo deste trabalho é trazer recomendações ergonômicas para o ambiente (as demais etapas são projetuais e estão relacionadas à construção da edificação).

Dentre as etapas abordadas neste estudo, o Briefing como primeira etapa de Design, buscou, através de entrevistas, coletar dados sobre os requisitos necessários ao ambiente para satisfazer algumas demandas do usuário. Na segunda etapa, Perfis de Usuários e Grupos de Ajuste, foi feita a caracterização dos usuários e foram identificados os grupos de usuários (diretos, indiretos), assim como suas características pessoais e o estado de uso do ambiente. A terceira etapa, a Análise da Tarefa, destinou-se a detalhar as atividades realizadas no ambiente pela usuária em foco, sendo verificados os requisitos necessários, posturas assumidas na realização das tarefas, condições e constrangimentos do ambiente, além de verificação antropométrica e aspectos de conforto ambiental (sendo estes dois últimos elementos investigativos incorporados à metodologia para complementar a identificação de problemas a serem solucionados). A quarta etapa, Adaptação às Necessidades dos Usuários, consistiu na compilação de todos os dados obtidos nas etapas anteriores, gerando, ao final, uma lista de recomendações ergonômicas.

\section{RESULTADOS}

\subsection{Briefing de Design}

O ambiente escolhido para o estudo referido foi uma área de serviço da habitação popular feita pela Caixa, do programa "Minha Casa, Minha Vida". Uma visão geral inicial nos faz perceber aspectos questionáveis no espaço, tais como a ausência de revestimentos e exposição ao sol. A figura a seguir nos permite observar o espaço de modo mais amplo.

Figura 1: Ambiente do estudo de caso

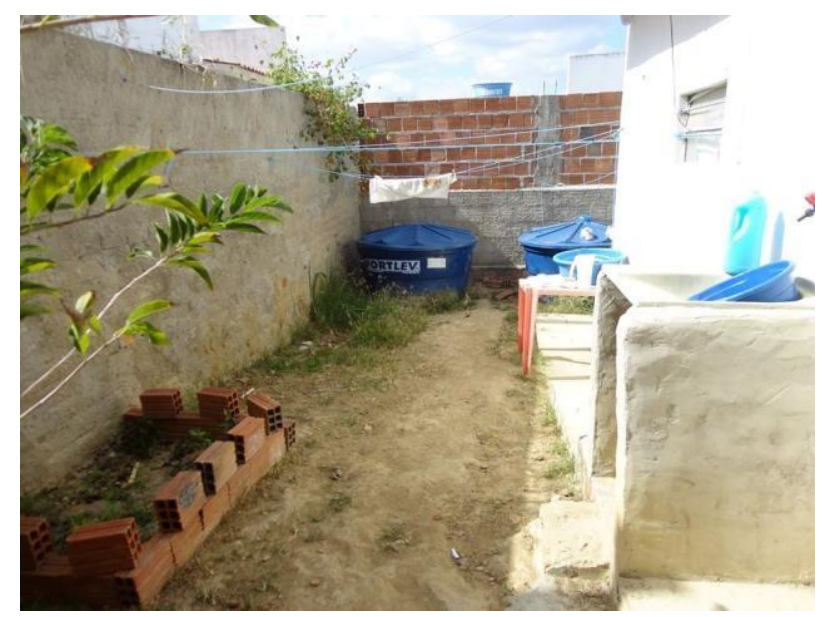

Fonte: Capturado pelos autores da pesquisa 


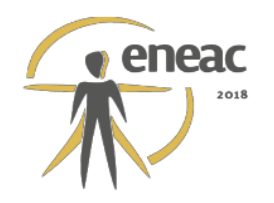

A usuária se queixa do piso do ambiente que não possui nenhum tipo de revestimento, estando sempre propício a tropeços e sujidades. Outro fator observado pela usuária é a falta de proteção contra os reagentes naturais (sol e chuva), que limitam o horário de realização das atividades neste espaço.

Em depoimento, a usuária transmitiu o anseio por uma adequação que considerasse um ambiente onde a área do tanque de lavar roupa fosse coberta, mas arejada, relatou também a necessidade de uma iluminação adequada, com menores índices de iluminância, considerando que os níveis atuais são bastante elevados, por conta da ausência de uma cobertura, o que tem provocado sudorese excessiva, dores de cabeça, ofuscamento e dores nos olhos. A usuária também aponta a necessidade de instalação de pontos elétricos, para tomadas e interruptores, e aproveitou para fazer um apelo pela inserção de um revestimento de piso com característica antiderrapante.

\subsection{Perfis de Usuários e Grupos de Ajuste}

A usuária direta é idosa aposentada de 77 anos que enfrenta vários problemas de saúde como: osteoporose; recuperação de fraturas nos membros superiores oriundas da osteoporose; catarata; e sofreu com Chikungunya, além de algumas cirurgias. A longeva tem a estatura de $1,45 \mathrm{~m}$, pesa atualmente $58 \mathrm{~kg}$, possui dificuldades em movimentar seus membros superiores em decorrência das fraturas que sofreu, além de sentir dores em todo o corpo devido às sequelas da Chikungunya.

Dentre os problemas de saúde que a usuária possui, também pode-se citar uma cirurgia de remoção das amígdalas, uma cirurgia de pedra na vesícula, e uma cirurgia de catarata. A usuária sofre com desconfortos por conta de uma fratura exposta no antebraço direito e uma outra fratura exposta no punho esquerdo, outro fator importante a se observar é a chikungunya que recentemente a atacou, potencializando esses desconfortos causados pelas fraturas. A usuária também sofre com uma suspensão na bexiga e perine, adquiriu inchaço e dores no joelho por conta do trabalho como costureira antes de se aposentar, além desses problemas de saúde, ainda possui osteoporose. Por enfrentar estas dificuldades de saúde, a idosa faz uso de 2 medicamentos ao dia, sendo 1 Calcitran D3 para os ossos, e Dorflex para dores musculares. Apesar de todas as dificuldades enfrentadas pela usuária, esta realiza sozinha as suas atividades domésticas.

Os usuários indiretos são: sua filha de 44 anos, que pesa $67 \mathrm{~kg}$ atualmente, $1,58 \mathrm{~m}$ de altura, não possui necessidades específicas e frequenta a casa da idosa em média dois dias por semana; seu neto, de 27 anos, que pesa atualmente $71 \mathrm{~kg}$, com estatura de $1,61 \mathrm{~m}$, não possui necessidades específicas, frequenta a casa da idosa em média cinco dias por semana. Ambos ajudam nas atividades da casa, como lavar a louça, varrer o chão, exceto nas atividades exercidas na área de serviço e na cozinha com o preparo de refeições e na lavagem de roupas.

Em posse das informações acerca dos usuários diretos e indiretos, realizou-se um Walkthrough detalhado, o qual permitiu a visualização dos diversos elementos compositivos do espaço. Verificou-se então o ambiente é localizado no térreo, tendo uma área retangular de $24,8 \mathrm{~m}^{2}$ e $1,3 \mathrm{~m}$ de circulação central no espaço de menos dimensão. Existe 1 janela e 1 abertura de acesso, além de 1 árvore frutífera (pinha) e 2 caixas d'água com capacidade de mil litros cada, também existe um taque de lavar roupas e uma mesa. $\mathrm{O}$ ambiente possui bastante aeração e iluminação natural, pois não há cobertura, e um alto índice de temperatura nos horários mais quentes. As paredes contam com acabamento, apenas cimento, e o piso é de terra batida. 


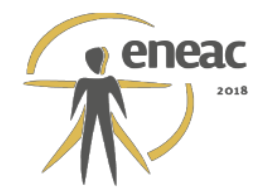

\subsection{Análise da Tarefa}

\subsubsection{Considerações sobre as Posturas Corporais}

Essa etapa consiste na observação detalhada das posturas assumidas para a realização das atividades que deverão ser executadas pela usuária envolvida.

a) Tarefa 1 - pegar água no reservatório: a usuária precisa abaixar-se a fim de apanhar a água na caixa d'água localizada no piso, flexionando o tronco, e consequentemente gerando desconfortos na região da coluna lombar. A usuária precisa transportar essa água para o tanque de lavar roupa, contando com equilíbrio e força dos membros superiores, ombros e costas. A caixa d'água possui uma tampa de abertura, dificultando ainda mais o acesso a água por parte da usuária.

Figura 2: Tarefa de pagar água no reservatório

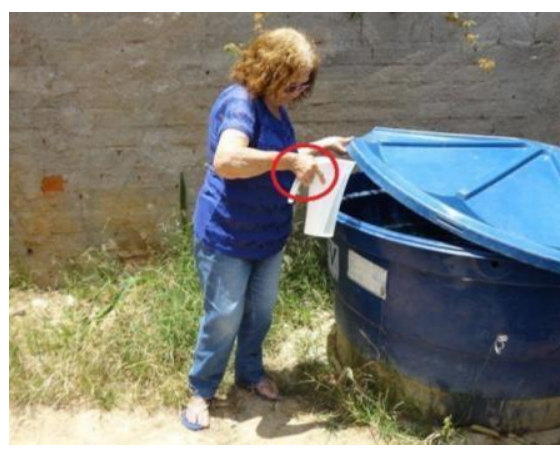

Fonte: Capturado pelos autores da pesquisa

Nesta mesma figura pode-se perceber que o recipiente utilizado pela usuária para transportar a água, causa uma inclinação no punho da usuária, podendo gerar vários desconfortos e dores, pois além da flexão no punho, existe também a carga concentrada no recipiente.

b) Tarefa 2 - transporte da água coletada no reservatório: o transporte de carga é realizado com frequência (recipientes com água). A atividade é prejudicial por conta de a idosa ser acometida por problemas de saúde como osteoporose, e dores articulares decorrentes da Chikungunya, além das limitações normais causadas pela idade e o sobrepeso, que deixam a usuária menos resistente a fadiga. As áreas mais afetadas são trapézio, membros superiores, joelhos e a coluna completa.

Figura 3: Transporte da água coletada no reservatório

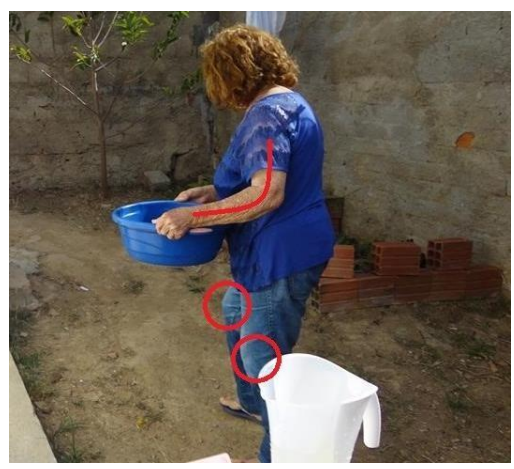

Fonte: Capturado pelos autores da pesquisa. 


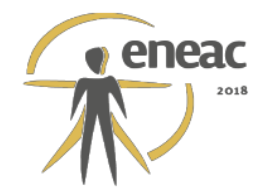

Esse processo se faz necessário pela ausência de água na torneira, um problema enfrentado por muitos nos últimos dias, em que se agrava pois, a casa dispõe de uma caixa d'água pequena, não permitindo o armazenamento de grande quantidade de água, forçando a usuária a transportar a água dos demais recipientes para o lavatório, problema que poderia ser facilmente resolvido com uma instalação adequada.

c) Tarefa 3 - pôr água dentro do lavatório: a atividade consiste em passar a água contida na bacia para o tanque de lavar roupa, e para que ela seja realizada, a usuária necessita elevar os membros superiores, segurando grande quantidade de carga, com o peso distante do ponto de equilíbrio (seu corpo), causando dores nos ombros e nas regiões da coluna cervical e lombar, encurvando também os punhos, forçando ambos.

Figura 4: Tarefa de pôr água dentro do lavatório

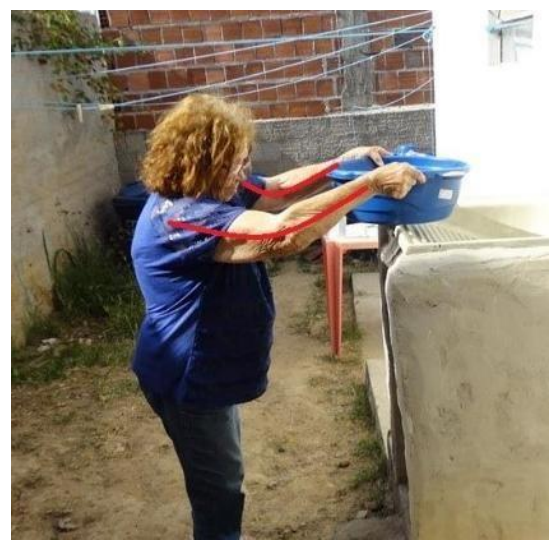

Fonte: Capturado pelos autores da pesquisa.

Essa atividade é realizada com rotina pela usuária e requer muito esforço, o problema tornase decorrente pela altura em que a superfície da pia se encontra.

d) Tarefa 4 - apanhar produtos de limpeza e objetos: esta atividade causa preocupação quanto à postura e esforço da usuária durante o ato de apanhar objetos e produtos no piso, pois, para recolher, é necessário que ela flexione bastante o tronco, forçando a coluna vertebral e os membros inferiores (os quais sofrem pela perda de tônus muscular).

Figura 5: Tarefa de apanhar produtos de limpeza e objetos

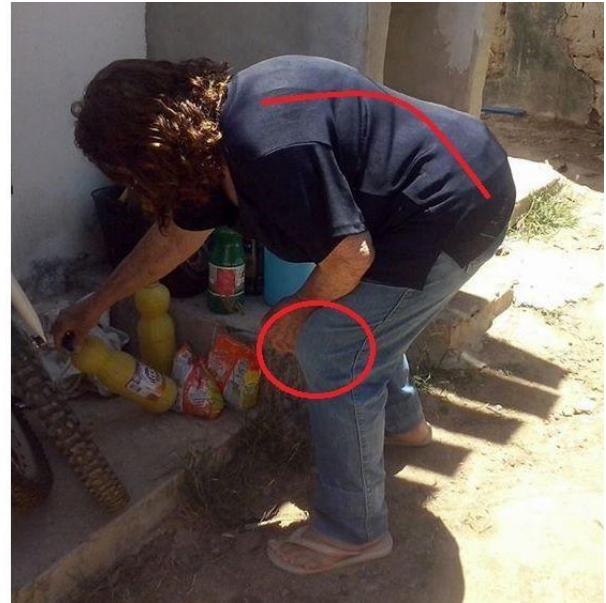

Fonte: Capturado pelos autores da pesquisa. 


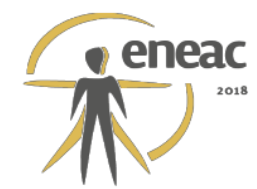

Essa tarefa costuma ser rotineira, já que não existe um local específico para o armazenamento de materiais de limpeza, visto que é necessário, constantemente, o uso desses materiais para as atividades do dia a dia.

e) Tarefa 5 - utilização do tanque de lavar roupas: devido à estatura da usuária e à construção em local inadequado do tanque de lavar roupa onde existe um desnível, nota-se um grande esforço por parte da usuária a fim de utilizá-lo. O batente construído posteriormente, possuí altura de $11 \mathrm{~cm}$ e $22 \mathrm{~cm}$ de profundidade, o qual é utilizado como apoio para a usuária.

Figura 6: Utilização do tanque de lavar roupas

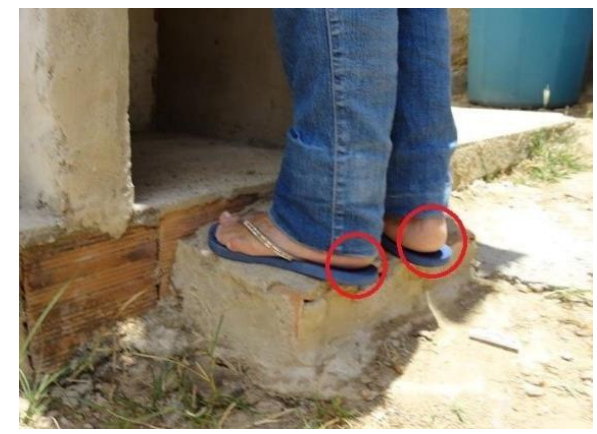

Fonte: Capturado pelos autores da pesquisa.

Como observado na figura 6 , o batente é pequeno e tende a causar desconforto, principalmente pela profundidade ser pequena, os pés da usuária não se apoiam por completo, trazendo um enorme risco de queda, incluindo fadiga e dores nos pés.

Tarefa 6 - utilização da torneira: a atividade de abrir a torneira, devido à altura encontrada no lavador, não oferece conforto à usuária analisada na pesquisa. A baixa estatura da usuária a impede de utilizar a torneira de forma adequada. É possível notar a flexão na coluna mediante o esforço realizado; o abdome sendo comprimido contra a bancada de trabalho; e os membros superiores elevados por longos períodos acima da altura do ombro.

Figura 7: utilização da torneira

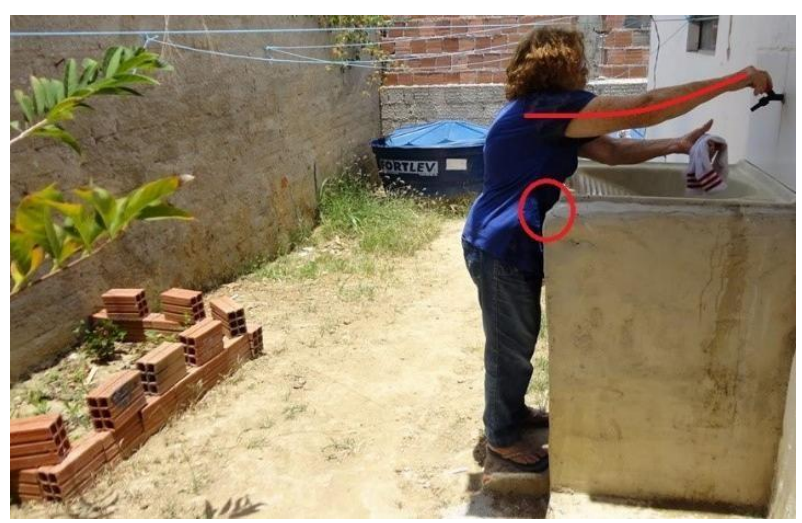

Fonte: Capturado pelos autores da pesquisa.

Conforme observado na figura 07 , torna-se possível verificar posturas que potencialmente podem vir a gerar dores e desconforto nas regiões de ombros e trapézio em decorrência dos esforços requeridos à usuária na utilização do tanque de lavar roupas. 


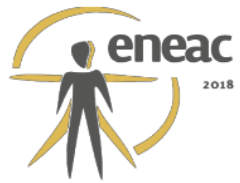

\subsubsection{Considerações Antropométricas}

Segundo a norma ABNT NBR 9050, para um ambiente possuir uma boa circulação, é necessário que o espaço esteja livre de obstáculos, destinado ao uso de todas as pessoas e os acessos devem permanecer livres de quaisquer obstáculos de forma permanente.

Considerando que as dimensões mínimas para uma o ambiente de lavanderia que é de $5 \mathrm{~m}^{2}$, o nosso ambiente é considerado grande, pois possui uma área de $24,8 \mathrm{~m}^{2}$, e não dispõe de uma grande quantidade de mobiliário ou obstáculos que impeçam a circulação central, onde esta, tem como menor medida 1,30m.

O ambiente não dispõe de uma grande quantidade de mobiliário ou obstáculos que impeçam a circulação central, a qual tem como medida 1,3m. Desta forma, a circulação do ambiente se mostrou adequada às recomendações de Panero e Zelnik (2013), que é de 121,9cm para este tipo de espaço.

No ambiente, o mobiliário é constituído de um tanque de lavar roupas. Verificou-se que a altura da bancada está inadequada, pois possui $94 \mathrm{~cm}$, e a recomendação de Panero e Zelnik (2013) para bancadas é de no máximo $91,4 \mathrm{~cm}$. Quanto à profundidade da bancada, encontra-se com dimensões adequadas de $57 \mathrm{~cm}$, enquanto as recomendações permitem até $66 \mathrm{~cm}$. A torneira encontra-se fora do envelope de alcance da usuária. O lavador não está adequado ao usuário também pelo acabamento de cimento precário, e ainda pelas quinas, que podem suscitar acidentes. Estas dimensões de adequação se evidenciam ainda mais preocupantes quando consideramos a análise da tarefa, que revelou a interação da usuária (de baixa estatura) com os artefatos.

Figura 8: Elemento de grande inadequação antropométrica.

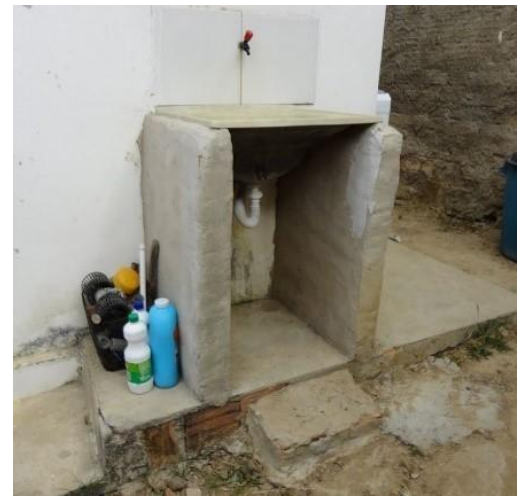

Fonte: Capturado pelos autores da pesquisa.

Desta forma, faz-se necessário que o tanque esteja a uma altura ideal para que a usuária não precise ficar na ponta dos pés para conseguir realizar sua atividade e não sofrer posteriormente pelo esforço. O mais confortável é que o tanque de lavar roupas esteja $10 \mathrm{~cm}$ abaixo da altura dos cotovelos dobrados. Também é importante que haja espaço para os pés debaixo da bancada, reduzindo a necessidade de permanência em constantes flexões de tronco.

\subsubsection{Considerações sobre Conforto Ambiental}

Para avaliar o conforto do ambiente analisado, foram usados aplicativos para aferir a temperatura, a ventilação, o ruído e a iluminação do local. Logo após os resultados foram 
comparados com as normas estabelecidas para o local, identificando se poderá ou não haver danos ou problemas futuros para a saúde da usuária.

A iluminação quando inadequada em um ambiente pode prejudicar a saúde física e psicológica do usuário, além de afetar seu rendimento nas atividades e acabar provocando um acidente (ABNT, 2016). Na visão, a má iluminação do ambiente pode causar irritação e os olhos podem lacrimejarem. Por isso, é importante que o ambiente esteja adequado de acordo com as recomendações de iluminação. Segundo a NBR 5413, o recomendado para o ambiente Lavandeira é entre 150 - 200 - 300lx.

Para medir a lluminância no local foi usado um Luxímetro devidamente calibrado. As medidas foram capturadas em dois horários diferentes: às 09 horas, que teve sua máxima de 835lx, e às 12 horas, que variou entre 11.002lx e 15.017lx.

Foi constatado, de acordo com as medidas realizadas, que o local possui muito mais que 0 recomendado para um ambiente do tipo lavanderia.

Para parâmetros de ventilação, a NR 17 recomenda que a ventilação do ambiente não ultrapasse $0,75 \mathrm{~m} / \mathrm{s}$ e que a umidade relativa do ar não seja inferior a $40 \%$. As aferições foram realizadas através do uso de um anemômetro e um higrômetro devidamente calibrados, foi constatada umidade relativa à $46 \%$, dentro dos parâmetros recomendados pela NR17. A ventilação identificou o valor de 2 a $3 \mathrm{~m} / \mathrm{s}$ às 9 horas, e $4 \mathrm{~m} / \mathrm{s}$ às 12 horas, ultrapassando o recomendado pela norma.

Sobre o ruído do ambiente, de acordo com a Organização Mundial de Saúde, o nível de ruído diário para que uma pessoa possa viver bem é de $55 \mathrm{~dB}$, os ruídos acima de $60 \mathrm{~dB}$ podem causar grandes prejuízos a saúde, como estresse emocional, dores de cabeça e ansiedade. $\mathrm{Na}$ área de serviços analisada, para identificar os decibéis encontrados no local, foi usado um Decibelímetro regularmente calibrado. Às 9 horas, o ruído não ultrapassou os $37 \mathrm{~dB}$, e às 12 horas, chegou aos $55 \mathrm{~dB}$, tendo, portanto, um nível de ruído adequado segundo as normas.

Para aspectos de temperatura, a NR-17 recomenda que o conforto térmico esteja entre os valores de $20^{\circ} \mathrm{C}$ e $23^{\circ} \mathrm{C}$. Porém, de acordo com o aparelho de termômetro adequadamente calibrado utilizado para a aferição, a temperatura alcançou os $31^{\circ}$, fora dos níveis recomendados pela norma.

\subsection{Adaptações as Necessidades dos Usuários}

Nesta etapa, foram consideradas as necessidades dos usuários, através de dados coletados na análise da tarefa foi gerado resumo dos problemas ambientais, e em seguida uma lista de recomendações ergonômicas.

Viu-se que o espaço que seria para higienização e lavagem de roupas e outros artefatos é um lugar desconfortável, cheio de problemas ergonômicos. A começar pelo piso, que não possui nenhum tipo de revestimento, é cheio de gramas e plantas de tamanhos consideráveis. O espaço é grande, mas não há um aproveitamento adequado. Ainda se tratando do piso, há um desnível que torna uma parte da área de serviço mais alta do que o outro extremo, formando um declive, causando problemas quando se transporta uma grande quantidade de água da caixa d'água para o tanque de lavar roupas.

As dimensões de alcance dos artefatos da área de serviço não condizem com a estatura e características físicas da usuária, como, por exemplo, a profundidade do tanque e o acesso ao mesmo. O acesso ao tanque pela usuária só se dá pela construção de um degrau para o alcance da torneira. Viu-se que o degrau é menor do que o tamanho do pé da usuária, que causa cansaço e dores no pé e no tornozelo. Além do que esta solução não impede as excessivas flexões de tronco e extensão com elevação de membro superior. 


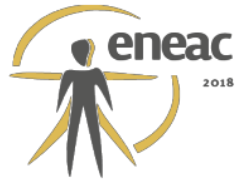

Não há água suficiente na caixa d'água localizada no teto da casa, implicando no transporte manual de água contida na caixa disposta na área de serviço. Também não há local adequado para guardar materiais de limpeza nem para colocar roupas e objetos sujos, o que implica na disposição destes artefatos no chão.

Para aspectos de conforto ambiental, nota-se que a iluminação natural apresenta índices muito altos, o que pode vir a prejudicar bastante a usuária. Por não existir cobertura, o ambiente fica totalmente desprotegido contra o vento, que pode derrubar roupas, equipamentos e até mesmo a usuária dependendo de sua velocidade. Essa falta de cobertura também implica bastante no fato de que, na maior parte do tempo, o ambiente possui temperaturas altíssimas em determinados horários, o que reduz bastante o horário em que a usuária fica a vontade para utilizar esse ambiente.

\subsubsection{Recomendações Ergonômicas}

- Instalar uma cobertura de proteção contra o tempo e os seus reagentes naturais como sol, chuva e aerodispersoides, além da iluminação natural que se torna exagerada pela ausência de cobertura;

- Instalar uma iluminação artificial adequada em todo esse espaço de área de serviço, utilizando lâmpadas frias com luz branca por conta da temperatura e também por causa da atividade, que exige da visão da usuária, visando assim o controle dos índices de iluminância e melhor conforto;

- Aplicar revestimento no piso, para proteção contra acúmulo de sujeira, animais que podem aparecer, vegetação indesejada, riscos de queda e acúmulo de lama ao derramar água. Optar por revestimento antiderrapante, pois a atividade na área de serviço utiliza água constantemente, e necessita de precaução com o risco de quedas;

- Aplicar revestimento nas paredes, pois elas estão apenas no cimento "bruto", sem ao menos reboco, o que acarreta um grande risco de lesão por arranhões e cortes;

- Instalar revestimento cerâmico para a área molhada, por conta do contato constante com a água utilizada na atividade de lavar roupas;

- Dispor de varais com algum sistema de regulagem de altura, para que fique no envelope de alcance da usuária, buscando eliminar desconfortos no ombro causados pela elevação dos membros superiores por muito tempo, além de lesões no pescoço, por manter a cabeça sempre olhando para cima;

- Substituir o lavatório por um com uma bancada de trabalho mais baixa e com menor profundidade, visando evitar lesões nos ombros por conta da elevação constante dos membros superiores, além de possíveis dores na região da coluna lombar e cervical por conta de posturas inadequadas. É interessante que as bancadas do ambiente sejam de uma altura onde a usuária consiga acessar sua superfície com os membros superiores em flexão de $90^{\circ}$.

- Instalar armários ou prateleiras dentro do envelope de alcance da usuária, para guardar os objetos e produtos de limpeza para realização das atividades. Optar por um mobiliário e puxadores que tragam familiaridade a usuária, evitando sistemas tecnológicos diferenciados. Aplicar diferenciações cromáticas nos elementos do mobiliário, permitindo contraste entre suas partes, considerando a perda de acuidade visual da usuária idosa e dificuldades na visão devido à catarata;

- Evitar objetos e equipamentos espalhados pelo espaço, para evitar que haja interrupções na circulação ou presença de obstáculos. 


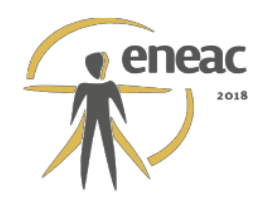

\section{CONSIDERAÇÕES FINAIS}

Considerando a relação entre a usuária do estudo de caso e o espaço ao qual ela estava inserida, notou-se que os problemas oriundos do processo natural de envelhecimento afetam diretamente o desempenho e a autonomia de idosos em espaços de áreas de serviço, demandando requisitos projetuais diferenciados. Desta forma ficou clara a necessidade de se conhecer bem o usuário, detectando suas limitações. A pesquisa nos apontou para o fato de que espaços projetados de forma generalista podem não atender às necessidades de usuários longevos, ainda mais intensamente quando se tratam de espaços adaptados ou informalmente construídos.

O estudo evidenciou que é possível gerar uma lista de recomendações ergonômicas voltadas para o usuário idoso acometido por diversos problemas de saúde. Ao projetar espaços direcionados a idosos, deve-se ter em mente a necessidade (imposta ou optada) de autonomia por parte destes usuários. Cabe lembrar que o projeto de um espaço que não considere o idoso, ou um erro projetual na concepção deste ambiente, pode significar um comprometimento severo da integridade física do longevo, considerando, inclusive, a interrupção de sua vida.

A execução da pesquisa também gerou observações de ordem antropométrica, quanto à busca por alcances adequados de mobiliário e equipamentos, visando resguardar futuras posturas assumidas. Além de visar um possível ganho de espaço para circulação através de mobiliário homogêneo, onde além de facilitar as atividades pertinentes a esse ambiente, melhora também a manutenção do próprio ambiente. Também se considerou o conforto ambiental, que também se revela como elemento bastante nocivo aos idosos.

As recomendações geradas neste estudo foram baseadas em pesquisas acerca do processo natural de envelhecimento, da osteoporose, da catarata, de fraturas e Chykungunia sofrida pela usuária direta do ambiente, o que implicou em uma maior atenção na postura corporal, alcances e limitações. Contudo, podemos destacar o fato de que as recomendações geradas podem ser utilizadas na adaptação do ambiente da área de serviços para qualquer idoso, assim como utilização por adultos sem a incidência de dificuldades ou inadequações. As recomendações estabelecidas ao fim desta pesquisa também poderão figurar como importantes requisitos para projetos ainda em fase de concepção. A análise deste estudo de caso, bem como das soluções propostas em formas de diretrizes de adaptação, poderão nortear futuros projetos. Neste sentido, seria possível elaborar ambientes adequados desde sua concepção, evitando a correção do ambiente apenas após a ocorrência do erro.

\section{REFERÊNCIAS BIBLIOGRÁFICAS}

ABNT, Associação Brasileira de Normas Técnicas, 2016. lluminação correta do ambiente de trabalho auxilia na saúde dos olhos. Disponível em: < http://www.boavontade.com/pt/saude/iluminacaocorreta-do-ambiente-de-trabalho-auxilia-na- saude-dos-olhos > acesso em: 10 de fevereiro de 2018.

CLARES, Jorge Wilker Bezerra; FREITAS, Maria Célia; BORGES, Cíntia Lira. Fatores sociais e clínicos que causam limitação da mobilidade de idosos. Universidade Estadual do Ceará, Fortaleza, CE, Brasil. In: Acta Paulista de Enfermagem, 2014; 27(3):237-42.

CHAU, D.L.; EDELMAN, S.V. Osteoporosis and diabetes. Clin Diabetes 2002.

NETO, Dr. Leôncio de Souza Queiroz. Catarata. Revista Boa Saúde, 2016. Disponível em: < http://www.boasaude.com.br/artigos-de-saude/4194/-1/catarata.html > Acesso em 14 de fevereiro de 2018. 
NIGHTINGALE S, HOLMES J, MASON J, HOUSE A. Psychiatric illness and mortality after hip fracture. Lancet, 2001.

ORGANIZAÇÃO MUNDIAL DA SAÚDE. Número de idosos quase triplicará no Brasil até 2050, afirma OMS, 2015. Disponível em: <

https://gauchazh.clicrbs.com.br/saude/vida/noticia/2015/09/numero-de-idosos-quase- triplicara-nobrasil-ate-2050-afirma-oms-4859566.html > Acesso em 10 de fevereiro de 2018.

ORGANIZAÇÃO DAS NAÇÕES UNIDAS. Mundo chega a 7 bilhões de pessoas; confira curiosidades e números. Disponível em: < http://g1.globo.com/mundo/noticia/2011/10/mundochega-7-bilhoes-de-pessoas-confira- curiosidades-e-numeros.html > Acesso em 10 de fevereiro de 2018.

SHAW, J.M., WITZKE, K.A. Exercise for Skeletal Health and Osteoporosis Prevention. In: ACSM'S RESOURCE. Manual for guidelines for exercise testing and prescription. 3.ed. Baltimore : Willians and Wilkins, 1998. p.288-239.

ZELNIK, Martin. PANERO, Julius. Dimensionamento humano para espaços interiores. Editora: GUSTAVO GILI, 2013. 